\title{
Los discursos sobre las drogas ilícitas en cuatro medios impresos colombianos*
}

\author{
Lina Marcela Pérez Arenas** \\ Elvia Elena Acevedo Moreno***
}

Recibido: 15 noviembre de 2012 - Aprobado: 23 de enero de 2013

\begin{abstract}
Resumen
Este artículo analiza el discurso acerca de las llamadas drogas ilegales en las columnas de opinión y editoriales de los periódicos El Tiempo, El Espectador y El Colombiano, y en los análisis y las columnas de opinión de la revista Semana, publicados durante tres momentos coyunturales (de 1986, 1996 y 2009). Se identificaron las ideas que predominaron alrededor de cuatro ejes: cuestionamientos, propuestas, consecuencias y causas. Además, se registraron los calificativos utilizados para referirse a la actividad de las drogas. El análisis indica que, en poco más de dos décadas, se pasó de reclamar acciones contundentes para combatir el tráfico de drogas y de demonizar la actividad, a pedir el replanteamiento de la estrategia de lucha contra ese fenómeno. Aunque las ideas de los artículos responden al momento histórico en que fueron escritos, los textos dan cuenta de la evolución del país respecto al tema de las drogas.
\end{abstract}

Palabras clave: Análisis de discurso, drogas ilícitas, medios de comunicación (Colombia), periodismo de opinión, periodismo interpretativo.

Este artículo presenta los resultados obtenidos a partir de una investigación realizada por las autoras y financiada por el Comité para el Desarrollo de la Investigación (CODI), de la Universidad de Antioquia. La investigación se tituló Consumo y tráfico de drogas ilegales. Un análisis de contenido sobre el tratamiento periodístico dado al tema en cuatro medios impresos colombianos, fue desarrollada entre enero de 2010 y diciembre de 2011, y en ella participaron, como coinvestigadora, la profesora Viviana María Garcés H.; como estudiantes en formación, Cristina Torres R. y Johanna Pino Q.; y como joven investigadora, Elizabeth Aristizábal G., todas de la Facultad de Comunicaciones de la Universidad de Antioquia.

.* Lina Marcela Pérez Arenas. Magíster en Ciencias Políticas y Comunicadora Social-Periodista, de la Universidad de Antioquia. Profesora de cátedra la Facultad de Comunicaciones de la misma institución. Miembro del Grupo de Investigación en Comunicación, Periodismo y Sociedad. Correo electrónico: linaperez@hotmail.com.

... Elvia Elena Acevedo Moreno. Doctora en Ciencias de la Comunicación, Universidad de São Paulo, Brasil. Magíster en Ciencias Políticas y Comunicadora Social-Periodista, de la Universidad de Antioquia. Profesora de planta de la Facultad de Comunicaciones de la Universidad de Antioquia. Miembro del Grupo de Investigación en Comunicación, Periodismo y Sociedad. Correo electrónico: elviaacevedo@yahoo.com.br 


\title{
Discourses on llegal Drugs in Four Colombian Journals
}

\begin{abstract}
This article analyzes the discourse about illegal drugs in opinion columns and editorials of El Tiempo, El Espectador and El Colombiano, and in Semana Journal, published in three special moments (1986, 1996, and 2009). Predominant ideas around four axis: questioning, proposals, consequences, and causes were identified. Besides terms used to refer to drugs activity were registered. The analysis indicates that in less than two decades, the claim for forceful actions to condemn and fight drugs business became a claim for a fight strategy against this phenomenon. Although the ideas of the articles correspond to the historical moment in which they were written, texts refer to the evolution of the country before the topic of drugs.
\end{abstract}

Key words: Discourse analysis, illegal drugs, communication media (Colombia), opinion journalism, interpretation journalism 


\section{Introducción}

A pesar de las varias convenciones prohibicionistas, se estima que el mercado mundial de las llamadas drogas ilegales es de unos 320 mil millones de dólares al año: "Si se tratara de un país, ocuparía el vigésimo primer lugar entre las economías del mundo" (Naciones Unidas, Oficina contra la Droga y el Delito, 2009). Asimismo, el Informe Mundial sobre las Drogas 2012 afirma que no ha habido cambios sustanciales en materia de consumo, producción y consecuencias sanitarias de las drogas ilícitas (Naciones Unidas, Oficina contra la Droga y el Delito, 2012).

Los analistas coinciden en que el combate contra las drogas no ha generado los efectos esperados. Además, hacen constantes críticas a las políticas adoptadas, como se puede observar en Camacho Guizado (2011), Tickner y Cepeda (2011), Charles (2010), Pardo (2010), Tokatlian (2009) y Vargas (2008). Otros, como Mejía (2011), Kopp (2010), Thoumi (2010), Tokatlian y Briscoe (2010) hacen referencia a los aspectos que deben tenerse en cuenta con miras a cualquier solución alternativa.

Poco a poco, tales críticas y alternativas han sido acogidas por diversos sectores sociales, de modo que cada vez se ventilan con mayor frecuencia en los medios de comunicación. Por eso, estudiar los discursos que sobre este tema se divulgan en los medios puede contribuir a entender las transformaciones de la sociedad en relación con el fenómeno de las drogas.

Y es que, como ya se ha comprobado, los medios tienen la capacidad no solo de proponer los debates sobre temas de interés público, sino que ejercen influencia acerca de qué pensar sobre esos mismos temas -teoría de la agenda setting (McCombs, 2006) y teoría de la espiral del silencio (Noelle-Neumann, 1995) - De ahí la necesidad de estudiarlos, de saber qué mensajes transmiten, cómo ellos están construidos, y qué lugar otorgan a ciertas problemáticas.

Cuando se trata de temas que sufren transformaciones a través del tiempo, como el de las drogas, uno de los caminos para estudiar los medios de comunicación es el de concentrar la mirada en la prensa escrita. Gracias a ella es posible recuperar el registro diario de los principales acontecimientos de un país y las reacciones que suscitaron. Además, como lo afirma la periodista Ana María Cano, por el prestigio que la prensa escrita tiene entre los medios electrónicos y, al mismo tiempo, por lo mucho que adopta de ellos, examinar los medios escritos puede "dar una idea completa del grado de comprensión o incomprensión que la comunicación masiva haya tenido" de los procesos sociales (Cano Posada, 1990, p. 21).

En este artículo se muestran los resultados de una investigación que examinó los discursos en relación con la actividad de las drogas ilegales, en los periódicos El Tiempo, El Espectador y El Colombiano y en la revista Semana.

\section{Metodología y corpus de la investigación}

Tradicionalmente, los textos periodísticos se han clasificado en dos grandes grupos: los informativos y los de opinión. Dentro del primero se encuentran géneros como la noticia, 
la entrevista, el informe especial, la crónica, el reportaje. En el segundo, la columna, el editorial, el comentario, la crítica, la glosa. Géneros interpretativos, como el del análisis, suelen ubicarse en el estilo informativo, aunque algunos lo clasifican en un grupo intermedio entre este y el de opinión'.

Aquí se presentan los hallazgos del estudio de los textos de opinión (columnas y editoriales) de los periódicos El Tiempo, El Espectador y El Colombiano; y de los textos de análisis y de opinión (columnas) de la revista Semana, todos en sus versiones impresas ${ }^{2}$. Se eligieron por ser los principales medios impresos del país, en cuanto a su prestigio en el ámbito mediático y al número de lectores ${ }^{3}$.

El objetivo, al estudiar los discursos de los textos seleccionados, fue identificar las ideas alli predominantes acerca de la actividad de las drogas.

Normalmente, los editoriales de los periódicos tienen los siguientes componentes: presentación de una situación, que suele hacer referencia a los sucesos recientes que son noticia; evaluación de dicha situación; y conclusión, es decir, alusión a las expectativas de futuros desenlaces y recomendaciones (Van Dijk, 1997). Las columnas de opinión no se alejan de tal esquema. Por otro lado, ambos tipos de textos se ubican dentro de los discursos argumentativos, cuyos propósitos son: influir, modificar las convicciones, ganar adhesiones e incitar a la acción (Perelman, 1997).

Aunque no podría decirse que los textos de análisis de la revista Semana tienen tales fines, la observación de su estructura indica que contienen los mismos elementos de los textos de opinión. Por eso, ambos grupos fueron estudiados bajo los mismos parámetros.

De este modo, las ideas en relación con la actividad de las drogas ilegales fueron clasificadas de acuerdo con los componentes arriba mencionados:

1 La discusión sobre los géneros puede apreciarse en Fernández Parratt, Sonia. (2001). El debate en torno a los géneros periodísticos en la prensa: nuevas propuestas de clasificación [on line]. Zer: Revista de Estudios de Comunicación 6 (11). Disponible en: http://www.ehu.es/ojs/index.php/Zer/issue/view/468/showToc [Consultado agosto, 2012]. Obsérvese también a López Hidalgo, Antonio. (2003). El análisis: cun género periodístico? [on line]. Ámbitos. Revista Internacional de Comunicación (9-10). Disponible en: http://grupo. us.es/grehcco/ambitos09.htm [Consultado agosto, 2012]

2 Los hallazgos en relación con el análisis de los textos informativos se presentan en Acevedo Moreno, Elvia Elena. (en preparación). Drogas ilegales: un análisis de contenido sobre el tratamiento periodístico dado al tema en tres diarios colombianos. Tal análisis se hizo con base en una muestra total de 1.035 piezas informativas de los periódicos El Tiempo, El Colombiano y El Espectador e incluyó las siguientes categorías: autor, géneros periodísticos, origen de la información, cantidad y tipo de las fuentes citadas, contraste entre los puntos de vista de las fuentes, ubicación de los artículos de acuerdo con las secciones de los medios y los cuadrantes de las páginas, y lugar donde suceden los hechos noticiosos.

3 De acuerdo con la Primera Ola del Estudio General de Medios de 2012, divulgada en el mes de mayo, en la categoría de diarios de interés general los tres periódicos ocupan los tres primeros lugares en el número de lectores diarios, así: 1’137.483, El Tiempo (los domingos: 1`921.571); 250.254, El Espectador (domingos: 472.224); 179.320, El Colombiano (domingos: 354.452) ("El Tiempo: más lectores diarios", El Tiempo, 13 de mayo de 2012, p.28). La revista Semana, por su parte, figuraba en agosto de 2011 como la primera en el país en el género de análisis y opinión, con 1'028.000 lectores ("Se mueve el ranking de las revistas", [online] KienyKe, 12 de agosto de 2011, Disponible en: http://www.kienyke.com/2011/08/12/se-mueve-el-ranking-delas-revistas/, [Consultado agosto, 2011]). 
- Presentación y evaluación de una situación: se observó que las columnas, editoriales y análisis cuestionaban diversos asuntos relacionados con las drogas ilegales. Al mismo tiempo, se referían a las causas de dicha problemática.

- Conclusión: asimismo, los textos hacían referencia a las consecuencias del fenómeno y proponían soluciones.

A esta clasificación se le denominó "ejes". Se hizo un conteo para determinar cuáles eran los ejes predominantes en los textos y se encontró que, en orden descendente, las ideas se agrupaban así: cuestionar, proponer, referirse a las consecuencias y a las causas. Un artículo, normalmente, incluye los cuatro ejes, y puede hacer énfasis en algunos de ellos. Además, los ejes se interrelacionan con frecuencia: por ejemplo, un trecho de un artículo puede formular una propuesta sobre un asunto que en líneas anteriores ha cuestionado.

Los hallazgos se muestran en términos generales, es decir, sin entrar a diferenciar las particularidades de cada uno de los medios, para así identificar las tendencias sobresalientes.

Para el análisis, sirvieron de referencia los trabajos de Antón (2006), Astorga (2003), Cárdenas (2010), Peñaranda (2010) y Sierra (2010), en los cuales se estudia la relación entre medios de comunicación y drogas ilícitas.

Ante lo extenso que puede significar el estudio de los discursos sobre drogas, se seleccionaron tres períodos coyunturales, de tres décadas diferentes, durante los cuales se presentaron hechos relevantes relacionados con dicha problemática y que dieron lugar a un gran despliegue mediático. Se incluyeron todos los artículos que hicieran alusión directa a las drogas ilegales (tráfico, traficantes, consumo, políticas, etc.), desde el momento en que se produjo el hecho que desató el despliegue hasta un mes después. Los períodos fueron:

1. Diciembre de 1986, cuando fue asesinado el director de El Espectador, Guillermo Cano Isaza, por orden del narcotráfico. A raíz del asesinato, el gobierno de Virgilio Barco expidió una serie de decretos que buscaban cercar a los cabecillas del negocio. Se producen otros hechos como la detención del narcotraficante Evaristo Porras y el atentado contra el exministro de Justicia Enrique Parejo González, quien ejercía como embajador en Hungría.

2. Marzo de 1996, cuando Estados Unidos descertifica a Colombia. La llamada política de Certificación fue implementada de manera unilateral por los Estados Unidos desde 1986, con el propósito de evaluar la lucha antidroga de las naciones. Se estableció que un país "descertificado" sufriría represalias en el campo económico principalmente, como la suspensión de preferencias arancelarias (Tokatlian, 1997). El 1 de marzo de 1996 Colombia fue descertificada por primera vez, aunque los argumentos esgrimidos por el Gobierno estadounidense tuvieron que ver con el llamado proceso 8.000, es decir, con el ingreso de dineros de la droga en la campaña presidencial de Ernesto Samper. La descertificación provocó una fuerte reacción por parte de sectores políticos, económicos y periodísticos de Colombia, que temieron las consecuencias negativas para el país. Al hecho también se sumaron noticias como la muerte de José Santacruz Londoño y la entrega de Juan Carlos Ramírez Abadía, ambos narcotraficantes. 
3. Febrero de 2009, cuando se pronuncia la Comisión Latinoamericana sobre Drogas y Democracia. La Comisión se creó en 2008 y sus pronunciamientos han tenido cierta divulgación en los medios de comunicación debido a la participación de tres expresidentes de la región y de varios intelectuales (Comisión Latinoamericana sobre Drogas y Democracia, s.f.). Teniendo como contexto la reunión de la Comisión de Estupefacientes de la ONU que se realizaría en marzo de 2009, la Comisión Latinoamericana (2009) expidió una declaración en la que pedía un cambio de paradigma en este tema. Con motivo de dicho pronunciamiento, los medios produjeron una serie de materiales periodísticos en los días siguientes.

El total de artículos analizados fue de 145, así:

\begin{tabular}{|l|c|c|c|c|}
\hline & $\begin{array}{c}\text { Primer período } \\
(17 \text { de diciembre } \\
\text { de 1986 a 17 de } \\
\text { enero de 1987) }\end{array}$ & $\begin{array}{c}\text { Segundo período } \\
\left(1^{\circ} \text { de marzo a 1 }\right. \\
\text { de abril de 1996) }\end{array}$ & $\begin{array}{c}\text { Tercer período (11 } \\
\text { de febrero a 11 de } \\
\text { marzo de 2009) }\end{array}$ & $\begin{array}{c}\text { Total artículos } \\
\text { publicados en } \\
\text { cada diario }\end{array}$ \\
\hline El Colombiano & 11 & 16 & 8 & 35 \\
\hline El Tiempo & 20 & 15 & 8 & 43 \\
\hline El Espectador & 22 & 18 & 3 & 57 \\
\hline Revista Semana & 4 & 3 & 36 & 14 \\
\hline $\begin{array}{l}\text { Total artículos publicados } \\
\text { en cada período }\end{array}$ & 57 & 52 & & \\
\hline
\end{tabular}

\section{Resultados}

Antes de mostrar los hallazgos en cada uno de los "ejes" en que se clasificaron las ideas, debe decirse que una abrumadora mayoría de los textos se refiere al tema del tráfico de drogas y en muchísima menor proporción al consumo: en los tres períodos hay un total de 1.080 alusiones al tráfico, y apenas 31 al consumo. En otras palabras, los discursos dan prioridad a la actividad conocida en Colombia como el "narcotráfico", mientras que invisibilizan la cuestión del consumo de drogas.

Lo anterior podría considerarse normal, ya que se sabe que los textos de columnistas y analistas son motivados fundamentalmente por los principales hechos noticiosos que los medios divulgan, y, por lo menos en el primero y segundo períodos, tales hechos tuvieron que ver con la violencia generada por los traficantes y las políticas aplicadas para combatir esta actividad. Sin embargo, se esperaría que los artículos hicieran alusión de forma más integral a los distintos aspectos del fenómeno de las drogas entre los cuales debería resaltarse el del consumo, que, finalmente, forma parte del origen de la problemática.

\section{- $\quad$ Eje de los cuestionamientos}

El primero de los ejes alrededor del cual giran las ideas es el de los cuestionamientos: en total hay 426 trechos de los artículos que se ubican allí, en los tres períodos. El qué se cuestiona varía en cada uno de ellos. 
Así, en el primer período los artículos se enfocan en las acciones y en el tipo de medidas emprendidas por el Estado para contrarrestar el "narcotráfico"; de los 96 cuestionamientos, se encuentran 65 menciones de este tipo. Dos ejemplos:

\begin{abstract}
El Noticiero de las 7 presentó un informe sobre las medidas tomadas por el Ejecutivo después del asesinato del ministro Rodrigo Lara Bonilla y las comparó con aquellas promulgadas después de la muerte de don Guillermo. Prácticamente eran las mismas. Y conocemos sus resultados. Por ello, a lo sumo algunos jefes segundones del narcotráfico serán apresados y se convertirán en chivos expiatorios. El Estado se lavará las manos, y el país seguirá implorando justicia. (Bibuowicz, 1987, p. 3A).

A pesar de centenares de allanamientos y motos fuera de circulación y sospechosos retenidos, el país no deja de experimentar la sensación de que no estamos yendo tan lejos como podríamos en la guerra contra el narcotráfico (Rivera Salazar, 1987, p. 2A)
\end{abstract}

Como se observa, se interpela al Estado y se le piden medidas efectivas contra el tráfico de drogas. Desde luego, en ese momento, los articulistas escriben en el contexto de lo que el investigador Juan Gabriel Tokatlian (1997) denomina como la "norteamericanización" de la guerra contra las drogas, es decir, la aplicación en Colombia de las políticas que los EE. UU. han diseñado en relación con este fenómeno. Así, cuestionar la conveniencia de tales políticas o insinuar la posibilidad de explorar alternativas son posiciones que no aparecen (o por lo menos no sobresalen) en este primer período.

Con un menor número de menciones, en el primer período los artículos cuestionan otros aspectos, entre ellos, la corrupción que ha generado y la tolerancia que se ha tenido con el narcotráfico (16 menciones).

En el segundo período los cuestionamientos cambian de foco: de las 176 oportunidades en que los artículos hacen algún tipo de cuestionamientos, 123 se centran en controvertir la política de descertificación. Básicamente, se refieren a la "doble moral de los EE. UU." y a la "injerencia en la política interna colombiana":

[...] para nadie es un secreto que los Estados Unidos surten de narcóticos a Europa, mediante la producción de droga sintética en laboratorios clandestinos, como lo revela un informe de la Junta Internacional de Fiscalización de Estupefacientes, de las Naciones Unidas. ¿Pero quién ronda al dueño y señor de la moral del planeta? (El Colombiano, 1996a, p. 5A)

[...] cuanto en el Congreso norteamericano ha sido expresado tiene en especial para las naciones de nuestro hemisferio el significado de una amenaza de intervención descarada y de previsibles consecuencias en el manejo de nuestra política interna y el libre ejercicio de nuestras soberanías nacionales (El Espectador, 1996, p. 2A).

A propósito de este punto, Peñaranda (2010) encontró que "para la prensa colombiana de finales de los años setenta el problema de las drogas en Colombia tenía claramente un origen externo: Estados Unidos".

De otro lado, con 26 menciones (10 más que en el primer período), el asunto de la corrupción y de la tolerancia con el tráfico de drogas aparece de nuevo en este segundo período: 
Aquí todos estábamos untados. El campesino que sembró coca, cannabis o amapola. El tendero que lo abastece. El buscavidas que acabó de cocinero, de mula o de sicario. El cajero y el gerente que se hacen gordos de vista. El juez y el policía que engordan a ojos vistas. Los candidatos que llevaban años recibiendo a escondidas. Los marchants d'art con gusto de traqueto. El reportero o el ciudadano que no dijeron a tiempo. El Obispo que bendijo a Medellín Sin Tugurios y Margarita Rosa que se alojó en el Inter. Tal vez usted también, que negoció algún dólar o entró a un San Andresito... (Gómez Buendía, 1996, p. 5A)

En su recorrido por el discurso sobre las drogas en la prensa colombiana, Peñaranda (2010) también encontró que, en los setenta, en la prensa "se revelaba que el poder corruptor asociado con los traficantes de drogas estaba creciendo en la sociedad colombiana [...]".

Aunque el tema de la "corrupción" y la "tolerancia" en relación con las drogas solo aparece en 42 oportunidades en el eje de los cuestionamientos, surge en los demás ejes del análisis durante los dos primeros períodos; es decir, como se verá más adelante, se menciona en las propuestas, consecuencias y causas. Parece natural que así sea si consideramos que los artículos se producen en el contexto de una sociedad permeada por la actividad de las drogas ilícitas en diferentes niveles, bajo mecanismos aceptados directa o indirectamente por todos los sectores, tal como lo han estudiado diversos autores (a propósito ver Duncan, 2011).

En este segundo período, también aparece cuestionado, aunque en menor cantidad, el modelo de lucha contra las drogas (14 menciones), entre otros.

En el tercer período del análisis, los 154 cuestionamientos que se encuentran se enfocan en la estrategia de la lucha contra las drogas (72 menciones). Es decir, aumentan sustancialmente las menciones a un asunto que no apareció en el primer período y que tuvo solo 14 referencias durante el segundo. Desde luego, este incremento se produce porque el contexto de los discursos es el de la declaración de la Comisión Latinoamericana sobre Drogas y Democracia que, justamente, exhortaba a las naciones a un cambio de paradigma. Sin embargo, no deja de ser significativa la variación de planteamientos entre 1986 -cuando se exigía mayor contundencia estatal en las acciones contra el tráfico-y 2009 -cuando se sugiere la revisión del modelo-. El cambio en columnas y análisis seguramente está reflejando el "ambiente propicio" que existe actualmente en el mundo para reconsiderar la llamada lucha antidrogas, según lo describen Tokatlian y Briscoe (2010), y que tiene que ver con aspectos económicos, políticos y con los resultados de prácticas alternativas ensayadas por países europeos.

En el tercer período, entonces, los editoriales, columnas y análisis señalan que la estrategia vigente ha fracasado:

El caso de Colombia es ilustrativo: después de realizar los más grandes esfuerzos que país alguno haya realizado en el nivel mundial para controlar el narcotráfico, hoy producimos el doble de cocaína que hace 10 años, los cultivos de coca se han extendido por todo el país y las mafias del narcotráfico se reproducen como la hidra de Lerna (Rangel, 2009, p. 53). 
Pero además, no se puede dar por cierto un sofisma, y es que el objetivo de la lucha contra las drogas es 'un mundo sin drogas'. Ello es ingenuo conceptualmente y políticamente imposible (Garzón Vallejo, 2009, p. 4A).

En segundo lugar, durante el tercer período los cuestionamientos tienen que ver con el llamado porte de la dosis mínima: en 54 oportunidades se cuestiona que el gobierno del presidente Álvaro Uribe esté proponiendo penalizarlo; y en 14, que se haya despenalizado. Otros temas, entre ellos el de la propuesta de legalizar las drogas, también son cuestionados.

\section{- $\quad$ Eje de las propuestas}

Después de los cuestionamientos, el eje alrededor del cual se agrupan las ideas durante los tres períodos es el de las propuestas (236 menciones). Nuevamente, el tipo de propuestas que se hacen está muy ligado al momento coyuntural que el país vivía.

En el primer período (cuando el asesinato de Guillermo Cano causa conmoción nacional e internacional), de las 88 propuestas que aparecen, 44 hacen un llamado a la unidad nacional, al patriotismo, a que los ciudadanos denuncien, protesten, se defiendan, y a que se indague por prácticas inmorales; esto último va de la mano con el segundo tipo de cuestionamientos de dicho momento según se explicó antes (la corrupción y la tolerancia):

Es la hora de pedir la solidaridad de los colombianos de bien, que es la gran mayoría, es la hora de unirnos contra las fuerzas del mal. [... las fuerzas democráticas pueden unirse para trabajar por Colombia en un momento de desolación que parece no dar espera (El Colombiano, 1986, p. 5A).

Es deber irrenunciable de los partidos políticos y de sus más altos dirigentes, por lo menos, emprender la tarea de limpiar el interior de sus propias casas. Entre tanto ese propósito no se lleve a cabo con valentía y estricto sentido de la justicia, poco será lo que se haya avanzado en el camino de la reivindicación moral del país (El Espectador, 1986, p. 2A).

El segundo tipo de propuestas (con 23 menciones) que surgen durante el primer período es que se tomen medidas como la extradición y el combate militar a las drogas; además, que se fortalezcan las instituciones; es decir, se trata de propuestas que van paralelas a los cuestionamientos que se hacen al Estado, tal como se explicaba antes. Con 21 menciones, aparecen otras como que los medios informen responsablemente y que se repliquen modelos adoptados por otros países para combatir a las mafias.

En el segundo período, entre las 78 propuestas que se formulan, dos tipos prevalecen, cada una con 19 menciones: mesura para referirse a la descertificación que EE. UU. le aplicó a Colombia de modo que el conflicto entre ambos países no fuera mayor, y que el Estado actúe y adopte diversas medidas que contrarresten el tráfico de drogas y la interferencia de sus dineros. Tales propuestas tienen relación con el tipo de cuestionamientos que primó en ese momento y que, como se detalló antes, se centraron en la política de descertificación y en la corrupción y tolerancia frente a la actividad de las drogas. Algunos ejemplos: 
Tacto y diplomacia en los reclamos y en la búsqueda de nuevos horizontes económicos y políticos es lo recomendable en un momento difícil que no puede empeorar a punta de ligerezas y de palabras irresponsables. No estamos en posición de ser altaneros. [...] "Al buen callar, llaman..." (El Colombiano, 1996b, p. 5A).

Financiación de campañas por parte del Estado, endurecimiento de la ley electoral y penal para evitar que volvamos a lo de hoy, listas únicas de partido (lo que conlleva la realización de primarias para evitar el famoso dedo) y comités de ética serios que avalen la prestancia de los candidatos y la actuación de los mismos una vez elegidos, son algunas de las propuestas que hay sobre el tapete de la reforma electoral (Santos, 1996, p. 5A).

Entre las propuestas del segundo período también aparecen las de que se haga un cambio en el paradigma de la lucha contra las drogas (con 14 menciones), y, tal como en el primer período, que haya unidad nacional (con 10 menciones). Con 16 menciones, otras se refieren a que se adopten modelos de otros países y a que se cree una instancia supranacional de combate a las drogas.

En el tercer período, de las 70 propuestas surge con contundencia la de reformular la estrategia de lucha contra las drogas (50 menciones), asunto que, justamente, es lo que también se cuestionó en mayor volumen en ese momento:

[...] se puede empezar a construir un gran movimiento mundial de líderes políticos, gobiernos y forjadores de opinión, que impulsen a la nueva administración de Estados Unidos a reformular la ineficaz y dañina política antidrogas (Valencia, 2009, p. 4 A).

La manera en la que el mundo enfoca el problema del tráfico y consumo de drogas es indefendible. Todos los analistas objetivos que han examinado el tema concluyen que el régimen actual requiere una urgente y profunda reforma (Naím, 2009, p. 27A).

Puede decirse que estos planteamientos que se dan en los discursos del tercer período de alguna manera contribuyen a contrarrestar una de las características de los medios de comunicación que consiste en priorizar en sus informaciones la visión oficial y dejar por fuera los debates realizados por académicos (Sierra, 2010; Astorga, 2003).

Otras propuestas aparecen en este tercer período con menor intensidad: apoyar al gobierno (5 menciones), buscar aliados internacionales (5), legalizar la droga (4), penalizar la dosis mínima (3), entre otras.

\section{- Eje de las consecuencias}

El tercer eje que aglutina las ideas es el de las consecuencias de la problemática de las drogas: se encuentran 69 menciones en el primer período, 37 en el segundo, y 8 en el tercero.

En el primer período tales consecuencias tienen que ver con la corrupción (20 menciones), la violencia (15), el temor y la desesperanza (10) y, en menor cantidad, con la censura a la prensa, el desprestigio internacional, el debilitamiento del Estado y la impunidad, entre otras: 
Desafortunadamente a esto hemos llegado porque el país está absolutamente narcotizado. Eso es así. Las mafias ya están enquistadas estratégicamente en el poder. Solamente aguardan con paciencia y terror a tomárselo (Ayatollah, 1986, p. 5A).

En el segundo período las consecuencias apuntan fundamentalmente al desprestigio internacional que causaría para Colombia la descertificación dada por los EE. UU. (18 menciones), y el impacto económico que la medida traería para el país (15 menciones):

En el campo político es evidente el desprestigio que implica para Colombia el ser señalado como paria a nivel internacional, al quedar en el mismo saco que Afganistán, Birmania, Irán, Nigeria y Siria. Esta situación debilita aún más la posición internacional del país y reduce el margen de acción de su política exterior (Semana, 1996, p. 32).

En el tercer período, las consecuencias que se señalan tienen que ver con la violencia que generan las drogas, sobre lo que en ese momento se informaba en abundancia especialmente en relación con México.

\section{- $\quad$ Eje de las causas}

El último eje alrededor del cual se aglutinan las ideas es el de las causas del fenómeno de las drogas. Se encontraron 78 menciones distribuidas entre el primer período (14) y el segundo (64).

En el primer período las causas apuntan básicamente a la debilidad e inmoralidad en el país. En el segundo, las causas tienen que ver con la descertificación dada a Colombia: se señalan de nuevo la corrupción y la tolerancia (21 menciones), el presidente Ernesto Samper (14 menciones), la política interna estadounidense (14), la falta de firmeza y la permisividad de las instituciones estatales (13 menciones), entre otras:

$[\ldots]$ porque todos de una manera u otra tenemos o tuvimos algo que ver con ese fenómeno nacional, es que los gringos nos pusieron el 'tate quieto' pues se aburrieron de aguantarse una creciente corrupción del narcotráfico que ya llegó a 'ligas mayores' (Santos, 1996, p. 5A).

Parecen insuficientes las 78 alusiones a las causas del fenómeno de las drogas que se encuentran en los artículos: de este tipo de textos es esperable que se aborde con profundidad dicho aspecto y más aún si consideramos que se trata de un asunto que viene marcando la vida colombiana desde hace más de 30 años. A propósito de este punto, el investigador Francisco Thoumi (2010) señala que para mejorar la efectividad de las políticas antidroga es fundamental estudiar las razones que hacen que las personas consuman y produzcan drogas ilícitas.

\section{- Los calificativos al tema de las drogas}

El análisis de los discursos también se detuvo en examinar el tipo de calificativos que se atribuyen a la actividad de las drogas ilegales. En total, durante los tres períodos se encontraron 226 trechos con diversos tipos de apelativos, siendo el primero de ellos el que registra un mayor volumen (153), en comparación con el segundo (59) y el tercero (14).

La turbación ocasionada por el asesinato del director del periódico El Espectador alimenta el tipo de calificativos que se otorgan en el primer período a la actividad del tráfico 
de drogas y a quienes la ejercen: prevalecen los calificativos que aquí hemos denominado "peyorativos" y aquellos que asocian la actividad con "el mal": "mafia cobarde que se mueve en las tinieblas y mata sin dar la cara" (Santos Calderón, 1986, p. 4A), "malévola actividad" (El Tiempo, 1987, p. 4A), "fuerzas del mal" (Child, 1986, p. 3A).

Resulta interesante observar que en la década de los veinte, en la prensa mexicana aparecían calificativos muy similares para referirse a las drogas (Astorga, 2003). Aquí en Colombia, a finales de los sesenta y comienzos de los setenta los diarios se referían a la marihuana como la "yerba maldita" (Peñaranda, 2010). Y en Uruguay, explica Antón (2006), la droga aparece en los medios de comunicación "[...] como una encarnación moderna del mal que amenaza a la sociedad en todas partes". Así mismo, Cárdenas (2010), en su exposición sobre la relación entre los medios y la construcción social de la realidad, afirma que los hechos relacionados con el fenómeno de las drogas han sido traducidos a un plano "[...] en el que el bien (lo aceptado, lo oficial) se enfrenta al mal (las drogas) y, por lo tanto, su uso y quienes las usen de algún modo serán antagónicos al sistema".

En el segundo período los calificativos se aplican a la descertificación dada por los EE. UU. a Colombia y están relacionados con el tipo de cuestionamientos que se detallaron antes. Así, con 27 menciones, la descertificación se considera una medida grave, injusta y arbitraria: "hecho de suma gravedad" (González Rodríguez, 1996, p. 5A), "decisión injusta" (Pombo, 1996, p. 19); en segundo lugar (19 menciones), se refieren a ella de manera peyorativa o sarcástica: "certificado de buena conducta" (El Colombiano, 1996a, p. 5A), "neocolonial" y "carnaval de la farsa" (Lozano, 1996, p. 5A).

En el tercer período, los calificativos coinciden en algo, aunque en menor proporción, con los utilizados en el primero: peyorativos y asociados "al mal"; problema; y como empresa o negocio.

\section{Conclusiones}

El estudio de los discursos de las columnas de opinión, editoriales y análisis sobre el tema de las drogas ilegales publicados en El Colombiano, El Tiempo, El Espectador y Semana durante los tres períodos coyunturales seleccionados muestra, en primer lugar, una concentración en el aspecto del tráfico y una omisión del consumo. Aunque en el tercer período los textos se refieren al tema de la dosis mínima, en general los discursos giran básicamente en torno a la actividad del tráfico y de las medidas para combatirlo. En otras palabras, los textos se pliegan a la coyuntura noticiosa de cada momento dejando por fuera el sensible asunto del consumo, que, finalmente, es uno de los que está en la base de la problemática de las drogas.

El segundo hallazgo que puede resaltarse es que los artículos hacen evidente el entrelazamiento de la actividad de las drogas con la sociedad colombiana, es decir, la corrupción generalizada y la tolerancia sostenida. Sin embargo, esto sucede en el primer período, luego del asesinato de Guillermo Cano, de quien se destaca su permanente actitud de denuncia en relación con el tráfico de drogas; y en el segundo, cuando se entiende que la descertificación otorgada a Colombia es una represalia de los EE. UU. por el ingreso del dinero de las drogas a la campaña presidencial de Ernesto Samper. En el tercer período el 
asunto desaparece y en su lugar sobresale la idea de cambiar de estrategia en el combate a las drogas, acogiendo así la propuesta de la Comisión Latinoamericana sobre Drogas y Democracia.

El tercer punto tiene que ver justamente con esta última idea. Mientras en el primer período se cuestionan las débiles medidas tomadas por el Estado contra el tráfico de drogas y, en general, se pide una acción más eficaz, diez años después, se cuestiona la política de la descertificación, y otros diez años más tarde, el modelo general de la lucha contra las drogas. Así, los textos son reflejo y a la vez impulsores del cambio de óptica que en el tema de las drogas se ha producido en los últimos tiempos.

Tal transformación se constata también -y este es el cuarto hallazgo- en el tipo de calificativos que se da a la cuestión de las drogas: en el primer período los apelativos son abundantes al asociar el tema con "el mal", pero la grandilocuencia va disminuyendo hasta llegar a un lenguaje más moderado en 2009. Es decir, se pasa de demonizar la actividad de las drogas, a pedir que se le dé otro tratamiento y hasta que se legalice, como llegan a plantearlo algunos.

Desde luego, la perspectiva frente al tema de las drogas que exhiben los discursos tiene que ver con el momento histórico en que fueron producidos. Sin embargo, cabría preguntarse qué pasaría si resurgiera en Colombia la figura del traficante violento, o si los EE. UU. descertificaran de nuevo al país cadoptarían los artículos una posición similar a la de años anteriores? En realidad, tal vez no haya vuelta atrás y lo que están reflejando columnas, editoriales y análisis, en general, es el fin de toda una política para enfrentarse a las drogas y el nacimiento de otras perspectivas.

En cuanto a lo metodológico, si bien al inicio se hizo referencia a Van Dijk y al esquema que presenta en relación con los editoriales, y a Perelman, en relación con los discursos argumentativos, en este trabajo no se ha hecho un análisis crítico del discurso propiamente dicho; ni un análisis del discurso desde lo lingüístico; tampoco se han examinado las técnicas argumentativas o los tipos de argumentos. El tamaño de la muestra habría dificultado dichos abordajes. Por eso, de lo que se trató aquí fue de clasificar las ideas que los textos expresan, relacionarlas con el contexto histórico en que fueron publicadas $\mathrm{y}$, en algunos aspectos, determinar sus similitudes con otros estudios realizados sobre medios y drogas. Es decir, un análisis de discurso que relaciona texto y contexto.

Sería necesario continuar con esta línea a propósito de recientes acontecimientos que están por fuera del período de esta investigación y sobre los cuales se han producido nuevos textos periodísticos: noviembre de 2010, cuando se realizó una consulta en California con la que se pretendía la legalización total de la marihuana; noviembre de 2011, cuando el presidente colombiano Juan Manuel Santos, en una entrevista para el diario inglés The Guardian, afirmó que estaría dispuesto a participar en una discusión mundial sobre la guerra contra las drogas; marzo de 2012, cuando el presidente de Guatemala, Otto Pérez, propuso desmontar la lucha; junio de 2012, cuando Pepe Mujica, presidente de Uruguay, radicó un proyecto para que sea el Estado el que venda la marihuana a los consumidores; y agosto de 2012, cuando el alcalde de Bogotá, Gustavo Petro, sugirió la creación de centros de consumo de droga. 


\section{Bibliografía}

Antón, Danilo. (2006). El concepto "drogas": desinformación en sociedades consumidoras periféricas [on line]. Revista Cultura y droga, (13), 123 144. Disponible en: http://200.21.104.25/culturaydroga/ downloads/culturaydroga1 1\%2813\%29_7.pdf [Consultado mayo, 2012].

Astorga, Luis Alejandro. (2003). Tráfico de drogas ilícitas y medios de comunicación. Ponencia presentada en la Conferencia Internacional Medios de Comunicación: guerra, terrorismo y violencia, Hacia una cultura de la paz, Universidad Iberoamericana México, D.F., 5-6 de mayo.

Ayatollah. (1986, 21 de diciembre). A la guerra, guerra. El Tiempo, p. 5A.

Bibuowicz, Azriel. (1987, 8 de enero). La nueva ciencia. El Espectador, p.3A.

Camacho Guizado, Álvaro. (2011). Narcotráfico: mutaciones y política. En Gaviria Uribe, Alejandro y Mejía Londoño, Daniel, (Comp.), Políticas antidrogas en Colombia: éxitos, fracasos y extravíos, (pp.331-356) Bogotá: Ediciones Uniandes.

Cano Posada, Ana María. (1990). Procesos sociales a la luz de la prensa. En Alcaldía de Medellín, Los periodistas se preguntan: Memorias del Primer Seminario Internacional de Periodismo. Hecho en Medellín (pp. 19-26) Medellín: Alcaldía de Medellín.

Cárdenas Jiménez, Federico. (2010). El fenómeno de las drogas y los medios masivos [on line]. Revista Cultura y droga, (17), 99-112. Disponible en: http://200.21.104.25/culturaydroga/downloads/ Culturaydroga 15\%2817\%29_8.pdf [Consultado enero, 2012].

Charles, Molly. (2010). La reducción de la demanda de drogas de las Naciones Unidas: un éxito o una percepción sesgada. En Tokatlian, Juan Gabriel, (Comp.), Drogas y Prohibición. Una vieja guerra un nuevo debate. (pp. 57-103) Buenos Aires: Libros del Zorzal.

Child, Jorge. (1986, 18 de diciembre). Justicia y dialéctica. El Espectador, p. 3A.

Comisión Latinoamericana sobre Drogas y Democracia. (s.f.). La comisión [on line] Disponible en: http://drogasydemocracia.org/biografias [Consultado 12 de mayo, 2009].

Comisión Latinoamericana sobre drogas y democracia. (2009). Drogas y democracia: hacia un cambio de paradigma [on line]. Disponible en: http://drogasydemocracia.org/files/2009/03/livro_espanhol_04. pdf [Consultado 12 de mayo, 2009].

Duncan, Gustavo. (2011). Crimen y poder: El filtro del orden social. En Giraldo Ramírez, Jorge (ed.); Naranjo, Alberto; Jaramillo, Ana María; Duncan, Gustavo. Economía criminal en Antioquia: Narcotráfico, (pp. 151-253) Medellín: Universidad Eafit, Proantioquia, Empresa de Seguridad Urbana.

El Colombiano. (1996a, 7 de marzo). "Con la guardia en alto" (editorial), p. 5A.

El Colombiano. (1996b, 14 de marzo). "El imperativo de la prudencia" (editorial), p. 5A.

El Colombiano. (1986, 20 de diciembre). "iQué silencio se oye!" (editorial), p. 5A.

El Espectador. (1996, 10 de marzo). "Frente a los Estados Unidos" (editorial), p. 2A.

El Espectador. (1986, 23 de diciembre). "Frente al narcotráfico" (editorial), p. 2A.

El Tiempo. (1987, 15 de enero). "Dos atentados" (editorial), p. 4A.

Garzón Vallejo, Iván. (2009, 5 de marzo). Otro paradigma contra las drogas. El Colombiano, p. 4A.

Gómez Buendía, Hernando. (1996, 13 de marzo). La culpa como disculpa. El Tiempo, p. 5A. 
González Rodríguez, Hernán. (1996, 9 de marzo). Nos descertificaron por corruptos. El Colombiano, p. 5 A.

Kopp, Pierre. (2010). Un análisis económico del tráfico de drogas y las políticas públicas. En Tokatlian, Juan Gabriel, (Comp.), Drogas y Prohibición. Una vieja guerra un nuevo debate, (pp. 58-105) Buenos Aires: Libros del Zorzal.

Lozano, Juan. (1996, 4 de marzo). 3.2, 3.1, 3. El Tiempo, p. 5A.

McCombs, Maxwell. (2006). Estableciendo la agenda. El impacto de los medios en la opinión pública y en el conocimiento. España: Paidós.

Mejía, Daniel. (2011). Políticas antidroga en el Plan Colombia: costos, efectividad y eficiencia. En: Gaviria Uribe, Alejandro y Mejía Londoño, Daniel, (Comp.), Políticas antidrogas en Colombia: éxitos, fracasos y extravíos, (pp. 69- 90) Bogotá: Ediciones Uniandes.

Naciones Unidas, Oficina contra la Droga y el Delito. (2012). Informe mundial sobre las drogas 2012. Resumen ejecutivo [on line]. Disponible en: http://www.unodc.org/documents/data-and-analysis/ WDR2012/Executive_summary_spanish.pdf [Consultado 4 de julio, 2012].

Naciones Unidas, Oficina contra la Droga y el Delito. (2009). Informe del Director Ejecutivo de la Oficina de las Naciones Unidas contra la Droga y el Delito ante Comisión de Estupefacientes $52^{\circ}$ período de sesiones [on line]. Disponible en: http://www.unodc.org/documents/commissions/ CND-Uploads/CND-52-RelatedFiles/CND-52-Documents/CND52-ECN72009-ECN152009-CRP4-S. pdf. [Consultado 21 de julio, 2009].

Naím, Moisés. (2009, 1 de marzo). Del 'prohibido fumar' al 'prohibido pensar'. El Tiempo, p. 27A.

Noelle-Neumann, Elisabeth. (1995). La espiral del silencio. Opinión pública: nuestra piel social. Barcelona: Paidós.

Pardo, Rafael. (2010). Hacia un nuevo pensamiento sobre drogas. Nueve anomalías sobre el paradigma convencional y dos propuestas de nuevos caminos. En Tokatlian, Juan Gabriel, (Comp.), Drogas y Prohibición. Una vieja guerra un nuevo debate, (pp. 12-26) Buenos Aires: Libros del Zorzal.

Peñaranda Contreras, Leandro. (2010). De 'marihuaneros' a 'mafiosos': transformaciones en los discursos de la prensa colombiana en los años sesenta y setenta sobre el 'problema de la droga'. Signo y Pensamiento, XXIX (57), 314-329. Disponible en: http://recursostic.javeriana.edu.co/cyl/ syp/index.php?option $=$ com_booklibraryEtask $=$ viewEid $=312$ Ecatid $=37$ Eltemid $=48$ |Consultado 12 de abril, 2012].

Perelman, Chaim. (1997). Imperio retórico: retórica y argumentación. Bogotá: Editorial Norma.

Pombo, Roberto. (1996, 5 de marzo). Decencia, brother. Semana, núm. 722, p. 19.

Rangel, Alfredo. (2009, 16 de febrero). Contra las drogas: nueva visión. Semana, núm. 1.398, p. 53.

Rivera Salazar, Rodrigo. (1987, 13 de enero). Guerra a medias. El Espectador, p.2A

Santos Calderón, Enrique. (1986, 21 de diciembre). iNo pasarán! El Tiempo, p. 4A.

Santos, Francisco. (1996, 5 de marzo). iPor desvergonzados! El Tiempo, p. 5A.

Semana. (1996, 5 de marzo, núm. 722). "El costo de la bofetada", pp. 32-34.

Sierra, Álvaro. (2010). ¿Hay una narrativa periodística independiente sobre las drogas? Las curiosas paradojas de la cobertura del narcotráfico [en línea] En: Knight Center for Journalism in the Americas y Open Society Foundations (Eds.). Cobertura del narcotráfico y el crimen organizado en 
Latinoamérica y el Caribe. Memorias del 8th Austin Forum on Journalism in the Americas. (pp.33-55). s.l. Disponible en: knightcenter.utexas.edu/ccount/click.php?id= 16 [Consultado 22 de mayo, 201 1].

Thoumi, Francisco. (2010). Debates recientes de la Organización de las Naciones Unidas acerca del régimen internacional de drogas: fundamentos, limitaciones e (im) posibles cambios. En: Tokatlian, Juan Gabriel, (Comp.), Drogas y Prohibición. Una vieja guerra un nuevo debate, (pp. 27-56) Buenos Aires: Libros del Zorzal.

Tickner, Arlene Beth y Cepeda, Carolina. (2011). Las drogas ilícitas en la relación Colombia-Estados Unidos: balance y perspectivas. En Gaviria Uribe, Alejandro y Mejía Londoño, Daniel, (Comp.), Políticas antidrogas en Colombia: éxitos, fracasos y extravíos, (pp.205- 234) Bogotá: Ediciones Uniandes.

Tokatlian, Juan Gabriel y Briscoe, Iván. (2010). Drogas ilícitas y nuevo paradigma: hacia un debate posprohibicionista. En Tokatlian, Juan Gabriel, (Comp.), Drogas y Prohibición. Una vieja guerra un nuevo debate, (pp. 387-407) Buenos Aires: Libros del Zorzal.

Tokatlian, Juan Gabriel. (2009). Hacia una larga guerra irregular. En Tokatlian, Juan Gabriel, (Comp.), La guerra contra las drogas en el mundo andino: hacia un cambio de paradigma, (pp. 11-16) Buenos Aires: Libros del Zorzal.

Tokatlian, Juan Gabriel. (1997). En el límite: la (torpe) norteamericanización de la guerra contra las drogas. Bogotá: Grupo Editorial Norma.

Valencia, León. (2009, 17 de febrero). Abrir el debate sobre drogas ilícitas. El Colombiano, p. 4A.

Van Dijk, Teun A. (1997). Racismo y análisis crítico de los medios. España: Paidós.

Vargas M., Ricardo. (2008). Colombia y el nuevo mercado de drogas ilícitas. En Galán, Juan Manuel; Thoumi, Francisco; Ramírez Tobón, William; y Vargas M., Ricardo. La batalla perdida contras las drogas. ¿̇legalizar es la opción?, (pp. 309-373) Bogotá: Fundación Seguridad y Democracia E Intermedio Editores Ltda. 